\title{
Surgical technical performance scores are predictors of late mortality and unplanned reinterventions in infants after cardiac surgery
}

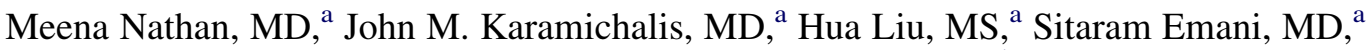
Christopher Baird, MD, ${ }^{\mathrm{a}}$ Frank Pigula, MD, ${ }^{\mathrm{a}}$ Steven Colan, MD, ${ }^{\mathrm{b}}$ Ravi R. Thiagarajan, MBBS, MPH, Emile A. Bacha, MD, ${ }^{\mathrm{c}}$ and Pedro del Nido, $\mathrm{MD}^{\mathrm{a}}$

Objective: We have previously shown that surgical Technical Performance Scores (TPS) are important predictors of early postoperative morbidity across a wide spectrum of procedures and that intraoperative recognition and intervention of residual defects resulted in improved outcomes. We hypothesized that these scores would also be important predictors of midterm outcomes.

Methods: Neonates and infants aged younger 6 months were prospectively followed from the index surgery for a minimum of 1 year. The TPS were calculated using previously published criteria, including intraoperative course, predischarge echocardiograms or catheterizations, and clinical data, and graded as optimal, adequate, or inadequate. Case complexity was determined by the Risk Adjustment for Congenital Heart Surgery- 1 category. The primary outcome was mortality, and the secondary outcome was the need for unplanned reinterventions. Outcomes were analyzed using nonparametric methods and a logistic regression model.

Results: A total of 166 patients were included in our study, with 7 early deaths. The remaining 159 patients (Risk Adjustment for Congenital Heart Surgery-1 category 4-6, 76 [48\%]; neonates, 78 [49\%]) were followed for a minimum of 1 year after surgery. There were 14 late deaths or late transplantations and 55 late reinterventions. On univariate analysis, the TPS were associated with mortality $(P<.001)$ and reintervention $(P=.04)$. On logistic regression analysis, inadequate TPS was associated with late mortality $(P<.001$; odds ratio, $7.2 ; 95 \%$ confidence interval, 2.2-23.6), and Risk Adjustment for Congenital Heart Surgery-1 category $(P=.004$; odds ratio, $3.7 ; 1.5-8.8)$ at index surgery was associated with need for late unplanned reintervention.

Conclusions: Technical performance affects midterm survival after infant heart surgery. Inadequate TPS can be used to prospectively identify patients at ongoing risk of demise and the need for reintervention. An aggressive approach to diagnosing and treating residual lesions at the initial operation is warranted. ( $\mathrm{J}$ Thorac Cardiovasc Surg 2012;144:1095-101)

\section{Supplemental material is available online.}

The outcome of congenital cardiac surgery, particularly in neonates and young infants, is dependent on multiple factors. These include preoperative physiologic status and disease complexity, intraoperative management, and

\footnotetext{
From the Departments of Cardiac Surgery ${ }^{\mathrm{a}}$ and Cardiology, ${ }^{\mathrm{b}}$ Children's Hospital Boston and Harvard Medical School, Boston, Mass; and Division of Cardiac Surgery, ${ }^{c}$ Morgan Stanley Children's Hospital of New York-Presbyterian, Columbia University, New York, NY.

Disclosures: Authors have nothing to disclose with regard to commercial support.

Read at the 92nd Annual Meeting of The American Association for Thoracic Surgery, San Francisco, California, April 28-May 2, 2012.

Received for publication April 25, 2012; revisions received May 29, 2012; accepted for publication July 30, 2012; available ahead of print Aug 30, 2012.

Address for reprints: Meena Nathan, MD, Department of Cardiac Surgery, Children's Hospital Boston and Harvard Medical School, 300 Longwood Avenue, Bader 273, Boston, MA 02215 (E-mail: meena.nathan@cardio.chboston.org). $0022-5223 / \$ 36.00$

Copyright (c) 2012 by The American Association for Thoracic Surgery http://dx.doi.org/10.1016/j.jtcvs.2012.07.081
}

postoperative events. ${ }^{1-6}$ In addition, human factors play an important contributory role. ${ }^{7-9}$

In initial work from our institution, ${ }^{10,11}$ we had developed a Technical Performance Score (TPS) for several individual procedures, including ventricular sepal defect repair, complete atrioventricular canal repair, tetralogy of Fallot repair, arterial switch operation, and stage I Norwood repair. The TPS grades the performance of the planned surgical procedure according to how closely the anatomic and functional result achieved the intended optimal outcome. In these studies, we have shown that the TPS correlates highly with the risk of complications and mortality and length of hospital stay in high-risk procedures. In a subsequent study, ${ }^{2}$ we were also able to show that in high-risk infants, an optimal technical score was able to mitigate the contribution of greater case complexity and greater preoperative illness severity.

In our latest published study, ${ }^{1}$ we prospectively followed 166 infants younger than 6 months of age, who underwent correction of congenital cardiac defects on cardiopulmonary bypass and found that technical performance 


\section{Abbreviations and Acronyms \\ RACHS-1 = Risk Adjustment for Congenital Heart Surgery-1 \\ TPS = Technical Performance Score}

correlated highly with the occurrence of major postoperative adverse events, after correcting for disease complexity and physiologic status. In our present study, we considered the midterm outcomes in the same cohort of patients. We hypothesized that the TPS would be able to predict the midterm outcomes and, thus, serve as a tool that could guide early intervention and ultimately improve long-term results.

\section{MATERIALS AND METHODS}

The institutional review board approved the present study.

In the initial cohort of 166 neonates and infants younger than 6 months old who had been followed prospectively from October 2008 to April 2010 from admission to discharge (data previously published), ${ }^{1} 7$ early deaths occurred. In the present study, the remaining 159 patients were followed after discharge from their index operation. Our endpoints of interest were mortality or the need for transplantation and the need for late intervention, either surgical or catheter based, or both, during the follow-up period, which ended March 2012.

Case complexity was scored using the Risk Adjustment for Congenital Heart Surgery-1 (RACHS-1) scoring system. ${ }^{4-6}$ The TPS was assigned according to the anatomic and functional information obtained from the discharge echocardiogram and clinical status at discharge from the index operation as optimal, adequate, or inadequate using a previously published method. ${ }^{10,11}$ The need for surgical or catheter-based reintervention for residual or recurrent lesions on the operated structures or the need for permanent pacemaker placement before discharge from index operation resulted in a TPS of inadequate.

Late mortality was defined as death or transplantation occurring more than 30 days after the index surgery for those patients discharged home less than 30 days after surgery. For patients discharged home more than 30 days after the index surgery, late mortality was defined as death or transplantation occurring any point after discharge.

Late reinterventions included any unplanned surgical or catheter-based intervention to treat a residual or recurrent lesion that occurred after discharge from the index surgery. For the purposes of the present study, for the neonates who underwent a Norwood stage I operation as their index procedure, a straightforward second-stage procedure or bidirectional Glenn procedure was not considered a reintervention.

\section{Statistical Analysis}

Categorical variables are represented as numbers and percentages, and continuous variables are summarized as median and range or mean \pm standard deviation. The Pearson $\chi^{2}$ test was used to compare proportions for categorical variables. A bivariate association was used to choose variables, with $P<.05$ for inclusion in logistic regression analysis. Multivariate logistic regression analysis was used to examine the association between technical performance and late outcomes, adjusting for age and case complexity. IBM SPSS Statistics, version 18, for Window (SPSS Inc, Somers, NY) was used for statistical analysis.

\section{RESULTS}

A total of 159 patients were included in the present study. Of these, $89(56 \%)$ were male, and $78(49 \%)$ were neonates at the index surgery. Of the 159 patients, $40(25 \%)$ were in RACHS- 1 category 2, 42 (26\%) were in RACHS- 1 category 3, 43 (27\%) were in RACHS-1 category 4, and 34 $(21 \%)$ were in RACHS-1 category 6 . The discharge TPSs were as follows: optimal in $59(37 \%)$, adequate in 77 $(48 \%)$, and inadequate in $23(14 \%$; Table 1$)$. Table E1 outlines the percentage of distribution of RACHS-1 categories in each of the TPS groups.

The mean duration of follow-up was $17 \pm 8$ months. The median duration of follow-up was 17 months (range, 1-35).

Of the 159 patients, 14 died or required late transplantation (4 late transplants). Of these 14 patients, 6 were in the optimal group $(10.2 \%), 1$ in the adequate group $(1.3 \%)$, and 7 in the inadequate group (30\%). Also, 55 patients $(35 \%)$ required 78 reinterventions.

The reinterventions included surgical or catheter interventions on the right ventricular outflow tract or main or branch pulmonary arteries in 37 patients; surgical or catheter interventions on the ascending aorta or arch in 10; surgical or catheter interventions on the Sano or BlalockTaussig shunt in 8; surgical or catheter interventions on the atrial septum in 4; surgical or catheter interventions on the pulmonary veins in 3 ( 2 after total anomalous pulmonary venous return repair and 1 after tetralogy of Fallot/absent pulmonary valve repair); surgical or catheter interventions on atrioventricular valve in 5 ; surgical or catheter interventions on systemic vein in 2; closure of residual atrial or ventricular septal defect in 2; late permanent pacemaker in 2; surgical intervention in subaortic region in 2 ; and transplantation in 4.

Table E2 outlines the initial index operation and indications for late reinterventions. Figures E1 to E6 depict the occurrence of mortality and the need for late reintervention according to TPS, RACHS-1 category, and age at intervention.

\section{Late Mortality/Transplantation}

On univariate analysis, a worse TPS was significantly associated with mortality $(P<.001)$. However, the RACHS -1 category and age at index surgery were not significantly associated with late mortality (Table 2). A significant association was seen between late mortality and late reinterventions $(P=.033$; Table E3).

On stratified analyses, mortality was greater in the inadequate group for both neonates and non-neonate infants and in both higher and lower RACHS categories (Table E4). This indicates that the greater mortality in the inadequate group did not result from confounding by either age or complexity.

On bivariate logistic regression analysis, an inadequate TPS was associated with greater late mortality compared with the risk of death in the optimal/adequate groups, adjusting for either age or RACHS category $(P=.001$; odds ratio, $7.2 ; 95 \%$ confidence interval, 2.2-23.6). We could 
TABLE 1. Patient characteristics

\begin{tabular}{lc}
\hline \multicolumn{1}{c}{ Characteristic } & Value \\
\hline Age at surgery (d) & \\
Median & 32 \\
Range & $0-156$ \\
Neonate & \\
Yes & $78(49 \%)$ \\
No & $81(51 \%)$ \\
RACHS-1 risk category & \\
2-3 (low risk) & $83(52 \%)$ \\
4-6 (high risk) & $76(48 \%)$ \\
TPS & \\
Optimal & $59(37 \%)$ \\
Adequate & $77(48 \%)$ \\
Inadequate & $23(14 \%)$ \\
Any late reintervention & \\
None & $104(65 \%)$ \\
Catheter based & $25(16 \%)$ \\
Surgical & $9(6 \%)$ \\
Catheter based and surgical & $21(13 \%)$ \\
Late death or transplant & \\
No & $145(91 \%)$ \\
Yes & $14(9 \%)$ \\
\hline
\end{tabular}

RACHS-1, Risk Adjustment for Congenital Heart Surgery-1; TPS, Technical Performance Score.

not adjust for age and complexity simultaneously owing to the relatively small number of deaths (Table 3 ).

\section{Need for Any Late Reintervention}

On univariate analysis, the TPS was significantly associated with the need for surgical or catheter-based reinterventions in the area considered inadequate $(P=.04)$, as were the RACHS- 1 category $(P<.001)$ and patient age at the index operation $(P=.02$; Table 4$)$.

On stratified analyses, no relationship was found between the TPS and the need for late reintervention in neonates. In older infants, however, the inadequate group was associated

TABLE 2. Univariate analysis of late mortality/transplantation

\begin{tabular}{lccc}
\hline \multicolumn{1}{c}{ Variable } & Patients (n) & Deaths $(\mathbf{n})$ & $\boldsymbol{P}$ value \\
\hline TPS & & & $<.001$ \\
$\quad$ Optimal & 59 & $6(10.2 \%)$ & \\
$\quad$ Adequate & 77 & $1(1.3 \%)$ & \\
$\quad$ Inadequate & 23 & $7(30.4 \%)$ & \\
TPS group & & & $<.001$ \\
$\quad$ Optimal/adequate & 136 & $7(5.2 \%)$ & \\
$\quad$ Inadequate & 23 & $7(30.4 \%)$ & \\
Neonate & & & .10 \\
$\quad$ Yes & 78 & $10(12.8 \%)$ & \\
$\quad$ No & 81 & $4(4.9 \%)$ & .27 \\
RACHS-1 category & & & \\
$\quad 2-3$ & 83 & $5(6.0 \%)$ & \\
4-6 & 76 & $9(11.8 \%)$ & \\
TPS, Technical Performance Score; $R A C H S-1$, Risk Adjustment for Congenital Heart \\
Surgery-1.
\end{tabular}

TABLE 3. Bivariate logistic regression analysis of late mortality/ transplantation

\begin{tabular}{lccc}
\hline \multicolumn{1}{c}{ Variable } & OR & $\mathbf{9 5} \% \mathbf{C I}$ & $\boldsymbol{P}$ value \\
\hline TPS for patient age & & & \\
$\quad$ Optimal/adequate & 1.0 & - & - \\
$\quad$ Inadequate & 7.2 & $2.2-23.6$ & .001 \\
$\begin{array}{l}\text { Neonate } \\
\quad \text { Yes }\end{array}$ & 2.3 & $0.7-8.0$ & .20 \\
$\quad$ No & 1.0 & - & - \\
$\quad$ TPS for RACHS-1 category & & & - \\
$\quad$ Optimal/adequate & 1.0 & - & -001 \\
$\quad$ Inadequate & 7.4 & $2.2-24.4$ & - \\
RACHS-1 category & & & .53 \\
$\quad$ 2-3 & 1.0 & - & \\
$\quad$ 4-6 & 1.5 & $0.4-5.0$ & \\
OR, Odds ratio; $C I$, confidence interval; $T P S$, Technical Performance Score; $R A C H S-$
\end{tabular}

1, Risk Adjustment for Congenital Heart Surgery-1.

with a greater reintervention rate $(P=.03$; Table E5). Similarly, no relationship was found between the TPS and reintervention in patients in higher RACHS-1 categories. However, among the lower RACHS- 1 categories, an inadequate TPS was associated with a greater rate of reinterventions $(P=.03$; Table E4).

On multivariate logistic regression analysis, RACHS-1 category $(P=.004$; odds ratio, $3.7 ; 95 \%$ confidence interval, 1.5-8.8) was significantly associated with the need for late unplanned reintervention. However, after adjusting for age and complexity, the odds of late reintervention were not significantly greater in the inadequate TPS group (Table 5).

\section{DISCUSSION}

The TPS of surgical procedures performed on young infants with congenital heart defects have been shown to correlate highly with early mortality and/or morbidity. ${ }^{1,2,11}$ In the present study, we have followed the same cohort of

TABLE 4. Univariate analysis of need for late reintervention factors associated with late reintervention

\begin{tabular}{lccc}
\hline \multicolumn{1}{c}{ Variable } & Patients (n) & Reintervention (n) & $\boldsymbol{P}$ value \\
\hline TPS & & & .04 \\
$\quad$ Optimal & 59 & $23(39.0 \%)$ & \\
$\quad$ Adequate & 77 & $20(26.0 \%)$ & \\
$\quad$ Inadequate & 23 & $12(52.2 \%)$ & \\
TPS group & & & .06 \\
$\quad$ Optimal/adequate & 136 & $43(31.6 \%)$ & \\
$\quad$ Inadequate & 23 & $12(52.2 \%)$ & .02 \\
Neonate & & & \\
$\quad$ Yes & 78 & $34(43.6 \%)$ & \\
$\quad$ No & 81 & $21(25.9 \%)$ & \\
RACHS-1 category & & & \\
2-3 & 83 & $17(6.0 \%)$ & \\
4-6 & 76 & $38(50.0 \%)$ & \\
TPS, Technical Performance Score; $R A C H S-1$, Risk Adjustment for Congenital Heart \\
Surgery-1.
\end{tabular}


TABLE 5. Multivariate logistic regression analysis of need for late reintervention

\begin{tabular}{lccc}
\hline \multicolumn{1}{c}{ Variable } & OR & $\mathbf{9 5} \% \mathbf{C I}$ & $\boldsymbol{P}$ value \\
\hline TPS & & & \\
$\quad$ Optimal/adequate & 1.0 & - & - \\
$\quad$ Inadequate & 1.8 & $0.7-4.6$ & .21 \\
Neonate & & & \\
$\quad$ Yes & 1.0 & $0.4-2.3$ & .98 \\
$\quad$ No & 1.0 & - & - \\
RACHS-1 category & & & - \\
2-3 & 1.0 & - & .004 \\
4-6 & 3.7 & $1.5-8.8$ & \\
\hline
\end{tabular}

OR, Odds ratio; $C I$, confidence interval; TPS, Technical Performance Score; $R A C H S$ 1, Risk Adjustment for Congenital Heart Surgery-1.

patients ${ }^{1}$ and found that the TPSs can also predict the midterm outcomes after correcting for other risk factors such as disease complexity and age.

In unadjusted analyses, the inadequate group was significantly worse than the optimal/adequate group with respect to occurrence of late death. Although the late mortality rates are greater in neonates and infants in higher RACHS categories, these differences are not statistically significant.

The stratified analyses suggest that mortality is greater in the inadequate group for both neonates and nonneonates and in both higher and lower RACHS categories. This indicates that the greater mortality in the inadequate group was not due to confounding by either age or procedure complexity. The relationship between inadequate technical performance and greater mortality remained after controlling for age, and for RACHS-1 risk category.

The relationship between TPS and late reintervention was weaker than the relationship between TPS and late mortality; however, there is still some evidence that the inadequate group is more likely to experience late reintervention than the optimal/adequate group. The rates of late reintervention were greater among neonates and those in greater RACHS categories. However, stratified analyses suggest that no relationship was found between the TPS and reintervention in neonates (rates of reintervention were consistently high in neonates compared with older infants, regardless of the TPS). In older infants, however, the inadequate group was associated with a greater reintervention rate. Similarly, no relationship was found between the TPS and reintervention in patients in higher risk categories. However, among the lower risk categories, inadequate TPS was associated with a greater reintervention rate. Thus, the TPS did not have a demonstrable effect on the reintervention rate in the highest risk infants. This observation might have been because of the greater mortality rate in this subgroup, such that an inadequate TPS in the higher complexity and risk procedures likely results in a more life-threatening abnormality in physiology. Alternatively, it could be that the nature of the TPS, because it is based on findings from the early postoperative echocardiogram, is not sensitive enough to detect subtle imperfections in technical performance that affect only late outcomes.

The present study cohort consisted of infants younger than 6 months old, with $49 \%$ neonates and $48 \%$ in the high risk RACHS- 1 categories. Thus, this cohort represented a relatively broad distribution across risk categories. We chose the postdischarge mortality and need for reinterventions as our intermediate outcomes of interest because these are well-documented hard endpoints. Despite the cohort size, our findings suggest that the TPS can predict the midterm outcomes. Although late mortality and the need for late reintervention are reasonable outcomes to follow, the rapidly improving outcomes of surgery for even the most complex of congenital defects suggests that more sensitive outcomes measures might need to be followed. To this end, we are also evaluating the neurodevelopmental outcomes in a subset of these patients to determine whether the technical performance correlates with this measure.

\section{Future Directions}

Mortality has long been used as an outcome measure, particularly for early outcomes in database research. However, several studies have shown that the use of mortality data might not effectively reflect a surgeon's performance because of the multiple associated factors that can contribute to mortality in any specific congenital cardiac diagnosis. ${ }^{12,13}$ Although risk adjustment does allow a more uniform comparison, the use of clinical and administrative databases to derive this information has the inherent problem of voluntary data submission and incomplete/ partial data collection. Few data are available on the long-term outcomes from such database research. Several initiatives are in place to unify data collection methods so more accurate and complete data can be accrued in each diagnostic group, ${ }^{14-20}$ particularly, long-term data such as late mortality and late reinterventions. The TPS can serve as a surrogate, and its inclusion into national and international databases could allow the expansion of this tool to a wider group of patients for validation.

\section{Study Limitations}

The present study included a small number of patients and in a specific age group. Additional study is required to validate this finding across a broad spectrum of diagnosis and procedures, and for all age groups.

Long-term data, not only on mortality, but also on more subtle outcomes, such as quality of life, neurodevelopmental outcomes, and psychosocial adjustments for the patients, as well as the family, might also be important measures of the efficacy of surgical performance in this group. ${ }^{21-23}$ Resource use in the form of multiple readmissions could be another important factor that should be measured. Whether the TPS might well serve as surrogate for 
measurement of these outcomes as well, not only in the short term, but also in the intermediate and long term, needs to be determined, because studies ${ }^{22,23}$ have shown that patient-related and environmental factors are more likely to contribute to neurodevelopmental outcomes in specific subset of patients such as those undergoing the Norwood stage I procedure and arterial switch operation.

Although this tool has been validated in 1 center for specific outcomes and specific subsets of patients, a multicenter study is necessary to establish its reproducibility across a wide range of diagnostic and procedural categories and across a wide range of programs. The use of echocardiography as the principle component of the TPS is advantageous, because it is routinely obtained perioperatively and during long-term follow-up in all centers. However, its disadvantage is the variability in the interpretation of the findings. We believe that standardization of the TPS modules will allow for more uniform data collection.

\section{CONCLUSIONS}

The TPS, based on early operative results determined by echocardiography at discharge and the need for early reintervention to correct residual or recurrent defects, correlates highly with both early- and intermediate-term outcomes. The present study underscores the need for early assessment of adequacy of the surgical procedure in addressing important hemodynamic lesions and justifies an aggressive approach to early intervention of residual defects.

We would like to acknowledge Kimberly Gauvreau, $\mathrm{ScD}$, for assistance with statistics, and Kathy Jenkins, MD, and the Program for Patient Safety and Quality for pilot funding of this project.

\section{References}

1. Nathan M, Karamichalis JM, Liu H, del Nido P, Pigula FA, Bacha EA. Intraoperative adverse events can be compensated by technical performance in neonates and infants after cardiac surgery: a prospective study. $J$ Thorac Cardiovasc Surg. 2011;142:1098-107.

2. Karamichalis JM, Thiagarajan RR, Liu H, Mamic P, Gauvreau K, Bacha EA. Stage I Norwood: optimal technical performance improves outcomes irrespective of preoperative physiological status or case complexity. J Thorac Cardiovasc Surg. 2010;139:962-8.

3. Karamichalis JM, del Nido PJ, Thiagarajan RR, Liu H, Jenkins KJ, Liu H, et al. Early post-operative severity of illness predicts outcomes following the stage I Norwood procedure. Ann Thorac Surg. 2011;92:660-5.

4. Jenkins KJ, Gauvreau K, Newburger JW, Spray TL, Moller JH, Iezzoni LI. Consensus-based method for risk adjustment for surgery for congenital heart disease. J Thorac Cardiovasc Surg. 2002;123:110-8.

5. Jenkins KJ, Gauvreau K. Center-specific difference in mortality: preliminary analyses using the Risk Adjustment in Congenital Surgery (RACHS-1) method. J Thorac Cardiovasc Surg. 2002;124:97-104.

6. Welke KF, Jacobs JP, Jenkins KJ. Evaluation of quality of care for congenital heart disease. Semin Thorac Cardiovasc Surg Pediatr Card Surg Annu. 2005; 157-67.

7. de Leval MR, Carthey J, Wright DJ, Farewell VT, Reason JT. Human factors and cardiac surgery: a multicenter study. J Thorac Cardiovasc Surg. 2000;119: 661-72.

8. Barach P, Johnson JK, Ahmad A, Galvan C, Bognar A, Duncan R, et al. A prospective observational study of human factors, adverse events and patient outcomes in surgery for pediatric cardiac disease. J Thorac Cardiovasc Surg. 2008; $136: 1422-8$.
9. Schraagen JM, Schouten T, Smit M, Hass F, van der Beek D, van den Ven J, Barach P. A prospective study of paediatric cardiac surgical microsystems: assessing the relationships between non routine events, team work and patient outcomes. BMJ Qual Saf. 2011;20:599-603.

10. Larrazabal LA, del Nido PJ, Jenkins KJ, Gauvreau K, Lacro R, Colan SD, et al. Measurement of technical performance in congenital heart surgery: a pilot study. Ann Thorac Surg. 2007;83:179-84.

11. Bacha EA, Larrazabal LA, Pigula FA, Jenkins KJ, Gauvreau K, Colan SD, et al. Measurement of technical performance in surgery for congenital heart disease: the stage I Norwood procedure. J Thorac Cardiovasc Surg. 2008;136:993-7.

12. Welke KF, Karamlou T, Ungerleider RM, Diggs BS. Mortality rate is not a valid indicator of quality differences between pediatric cardiac surgical programs. Ann Thorac Surg. 2010;89:139-46.

13. Stark JF, Stark J. Performance measurement in congenital heart surgery: benefits and drawbacks. Semin Thorac Cardiovasc Surg Pediatr Card Surg Annu. 2003;6: 171-83.

14. Jacobs JP, Wernovsky G, Elliott MJ. Analysis of outcomes for congenital cardiac disease: can we do better? Cardiol Young. 2007;17(Suppl 2):145-58.

15. Jacobs ML, Jacobs JP, Franklin RC, Mavroudis C, Lacour-Gayet F, Tchervenkov CI, et al. Databases for assessing the outcomes of the treatment of patients with congenital and paediatric cardiac disease-the perspective of cardiac surgery. Cardiol Young. 2008;18(Suppl 2):101-15.

16. Jenkins KJ, Beekman RH III, Bergersen LJ, Everett AD, Forbes TJ, Franklin RC et al. Databases for assessing the outcomes of the treatment of patients with congenital and paediatric cardiac disease - the perspective of cardiology. Cardiol Young. 2008;18(Suppl 2):116-23.

17. Vener DF, Jacobs JP, Schindler E, Maruszewski B, Andropoulos D. Databases for assessing the outcomes of the treatment of patients with congenital and paediatric cardiac disease-the perspective of anaesthesia. Cardiol Young. 2008 18(Suppl 2):124-9.

18. LaRovere JM, Jeffries HE, Sachdeva RC, Rice TB, Wetzel RC, Cooper DS, et al. Databases for assessing the outcomes of the treatment of patients with congenita and paediatric cardiac disease-the perspective of critical care. Cardiol Young. 2008;18(Suppl 2):130-6.

19. Welke KF, Karamlou T, Diggs BS. Databases for assessing the outcomes of the treatment of patients with congenital and paediatric cardiac disease-a comparison of administrative and clinical data. Cardiol Young. 2008;18(Suppl 2): 137-44.

20. O'Brien SM, Clarke DR, Jacobs JP, Jacobs ML, Lacour-Gayet FG, Pizarro C, et al. An empirically based tool for analyzing mortality associated with congenital heart surgery. J Thorac Cardiovasc Surg. 2009;138:1139-53.

21. Latal B, Helfricht S, Fischer JE, Bauersfeld U, Landolt MA. Psychological adjustment and quality of life in children and adolescents following open-heart surgery for congenital heart disease: a systematic review. BMC Pediatr. 2009;9:6.

22. Tabbutt S, Gaynor JW, Newburger JW. Neurodevelopmental outcomes after congenital heart surgery and strategies for improvement. Curr Opin Cardiol. 2012; 27:82-91.

23. Newburger JW, Sleeper LA, Bellinger DC, Goldberg CS, Tabbutt S, Lu M, et al. Early developmental outcome in children with hypoplastic left heart syndrome and related anomalies: the Single Ventricle Reconstruction Trial. Circulation. 2012;125:2081.

\section{Discussion}

David M. Overman (Minneapolis, Minn). Meena, congratulations on an excellent presentation and thank you for providing the report well in advance of the meeting for review.

This work builds on a characteristically expansive foundation of human factors research laid by Marc de Leval nearly 20 years ago. Human factors are, of course, quite complex and difficult to quantify. They include individual, technical, and organizational dimensions. Dr Bacha and his colleagues should be commended for successfully filtering out 1 specific human factor, intraoperative technical performance, and exploring its effect on outcomes through a series of investigations now dating back to 2007.

The present study assesses the role of the TPS on late mortality and unanticipated reintervention at a mean follow-up of 17 months. It extends the analysis of a prospective cohort of newborns 
and infants presented at last year's American Association for Thoracic Surgery, a study that demonstrated the ability of technical performance to mitigate the effects of adverse intraoperative events. The main findings of the present study are that the TPS is strongly associated with late mortality or the need for transplantation. Although this association is somewhat weaker when adjusted for age and complexity, it is particularly sobering to note that survival at 2 years is a startling $50 \%$ among patients whose TPS was inadequate.

Second, age and complexity did not correlate with late mortality or the need for transplantation, although this is probably explained by inadequate statistical power. The TPS is more weakly associated with late reintervention and in the report this association is limited to non-neonates and patients with lower complexity.

Finally, on multivariate analysis, complexity alone was associated with the need for late reintervention; notably, patients requiring reintervention had a mortality rate of $15 \%$.

I have 3 questions for the authors.

Number 1, it strikes me as counterintuitive that an inadequate TPS does not significantly increase the risk of the need for reintervention. The significant incidence of mortality among patients undergoing reintervention and the strong association of TPS with late mortality would seem to support a connection between TPS and reintervention. Can you share with us more specific information regarding the nature of these reinterventions, and does that data offer any explanation for this apparent paradox?

Dr Nathan. I would like to bring to your attention that in the initial cohort of 166 patients we had 7 early deaths, and most of them, 6 of the 7 were in the high-risk category and were in neonates, and 6 of the 7 had an inadequate technical performance. Thus, if these patients had survived, the chances are that they would have required multiple reinterventions or would have had late deaths.

Unfortunately, our study was underpowered, because we only had 159 patients. Also, if we had a larger subset of patients, we probably could prove that inadequate TPSs would definitely be associated with the need for late reintervention, in addition to late mortality.

Dr Overman. Second, the TPS is based almost entirely on postoperative echocardiographic assessment of residual disease. This method has some potential weaknesses. One of these is that by equating residual disease and technical performance, we introduce confounding variables that impair the evaluation of technical performance alone. For instance, what if the surgeon intentionally leaves a residual gradient at the level of the pulmonary valve during tetralogy repair, should that be considered technically less than optimal? Should imperfect native anatomy really effect TPS?

Dr Nathan. I agree that the TPS is not yet a perfect system, and we are in the process of tweaking it, particularly for certain diagnostic groups such as valve-sparing tetralogy repairs, valve repairs, and, in fact, even for canal repairs, because often in canal repairs, we accept trivial to mild regurgitation as acceptable, but that would classify it as an adequate score, rather than an optimal score.

We are in the process of modifying our TPS, and, hopefully, after we have accrued enough data on each of these subgroups, we might come up with a refined score.
Dr Overman. Finally, we all know that one can perform a technically perfect operation but still lose the patient to the hazards of the early postoperative environment, many of these hazards being human factors. Have the authors considered study designs that attempt measurement of other types of human factors, either alone or combined with TPS and whether there any human factors you would consider particularly important investigative targets for those in the audience who might want to take up the baton?

Dr Nathan. I agree with the discussant that there are several factors, in addition to technical performance, that will contribute to the outcomes and a many of them are human factors, namely, the cognitive factors, communication between the various teams involved in the care of the patient, both intraoperatively and postoperatively, and several other human factors that are closely interrelated. We concentrated on the TPSs and, hopefully, once we have refined it, we will study these other human factors, which we also believe play an important part in outcomes.

Dr Overman. Thank you and congratulations on this work.

Dr V. Mohan Reddy (Stanford, Calif). Meena, I would like to ask a question. I agree that technical performance is an important factor in early and late outcomes, but the paper is so abstract when you say "highly complex" and "interventions." Can you tell me 1, 2,3 , in each category, what were the most complex diagnoses, what were the 1,2, 3 residual defects that required reintervention.

Dr Nathan. I have a list of the 55.

Dr Reddy. Just give me the top 3 .

Dr Nathan. Most of them were pulmonary artery reinterventions. Most of them, in the stage 1 and in the Tet groups, especially the Tet pulmonary atresia MAPCAs, the other was arch interventions, and the third was either redo valve repair or subaortic interventions in the canals.

Dr Reddy. So how many were single ventricle or is this 2-ventricle patients who participated?

Dr Nathan. About $50 \%$ to $60 \%$ were single ventricle. A number of the reinterventions were in the single-ventricle group, which is to be expected. Even when they had an optimal technical performance, at their discharge echocardiogram, a number of them required reinterventions.

Dr Christopher A. Caldarone (Toronto, Ontario, Canada). Dr Nathan, it is no secret I am a big fan of this work that you have been pioneering. A couple questions.

One, I noticed on a couple of the slides, I think it was the late interventions, and it might have even been early mortality, that the "optimals" actually seemed to fare worse than the "adequates." I assume that was not statistically significant, but it was a bit of a trend. Do you have any explanation for that? Because it certainly would not have been expected.

Dr Nathan. The reason for that is a lot of the stage 1 cases, more than $50 \%$ of the stage 1 cases, were in the optimal group, but a number required either arch reintervention or reintervention on their shunts. We do have a very aggressive interventional cardiac program; and during pre-bidirectional Glenn cardiac catheterization, even if they see a minor arch gradient, they tend to balloon dilate, and those patients were included in our reintervention group.

Also, a number of the adequate group belonged in the low-risk RACHS category, namely, tetralogy of Fallot and canals; and, in them, even an adequate technical score did not seem to require late reintervention. Also, that might explain why the "adequates" 
seem to have done a little better in the various survival and reintervention curves than the optimal patients.

Dr Caldarone. However, your first example was that some patients, for example Norwood, might have had an optimal outcome in terms of the paradigm of the TPS but might have actually had a lesion that required reintervention.

Dr Nathan. Yes. Not at discharge but developed that lesion subsequently.

Dr Caldarone. Subsequently, I see.

Dr Nathan. Yes, they had an optimal score at discharge.

Dr Caldarone. So, presumably as your TPSs are modified and calibrated to the patient populations, they will come more in line with expectations and the prediction of reintervention.

Dr Nathan. Yes. We are in the process of accruing about 100 to 150 patients in each of these diagnoses so that we can further modify the TPSs.

Dr Caldarone. Do you think you will be adding additional parameters to measure, or will you be redefining the cutpoints among optimal, adequate, and inadequate?

Dr Nathan. We will initially redefine the cutpoints because we find that what we classify as mild regurgitation on discharge echocardiography in canals is often read as trivial on the follow-up echocardiogram, even though the vena contracta appears the same.

So, we will initially redefine the cutoff among optimal, adequate, and inadequate and then we will consider weighting each of the subcategories and procedures to determine which is more important and is more likely to need reintervention or cause an adverse outcome late during follow-up. For example, in a Norwood procedure, is arch reobstruction more significant than a restrictive atrial septum or a slightly narrow shunt? All of that needs to be redefined.

Dr Caldarone. So you redefine the cutpoints and add coefficients or weighting coefficients?

Dr Nathan. Yes.

Dr Marshall Jacobs (Newtown Square, Pa). I want to compliment you as everyone has. We have followed this research with great interest since the initial development of the tool. Also, one of my recollections of your earlier reports of the short-term outcomes and resource use is that the relationship between the TPS and those measures varied between procedure groups, that there are procedures for which suboptimal technical performance might be associated with longer hospital stay or different measures of outcome.

What you did in this study certainly makes sense. It is a very logical next step. But, really, this was an example of lumping, where the previous analyses were examples of splitting. Also, you really only stratified the patients here by their theoretical complexity as measured by RACHS, which is based on the estimated risk of mortality. So I wonder, going forward, as you accrue more data on more patients, as you have said you have to do, whether it will not be most appropriate to consider these midterm outcomes in relation to specific procedural groups.

I mean being left with a residual ventricular septal defect after a ventricular septal defect repair has very different physiologic consequences than being left with arch obstruction after a Norwood operation. Also, the overall expectations of a suboptimal outcome for 1 operation in terms of the survivability and functional status of the patient are very different than the overall expectations of the midterm outcomes for another operation.

So I compliment you on taking this to the next step, which was a natural progression, but I think really to find insights into the midterm associations with TPS, it is going to have to be broken down into procedural groups, isn't it?

Dr Nathan. I totally agree with you, and we are in the process of accruing these data. In our previous work on the initial presentation of 166 patients, we did show that an inadequate technical performance in the high-risk group was associated with increased mortality across all ranges. Thus, if you had an adequate technical performance, you did well if you were low risk, but did poorly if you were high risk. Also, if you had optimal technical performance, you did relatively well in all risk categories. We agree that considering specific procedures will give us a better insight into what lesions need preemptive reintervention. 
\% Late Mortality

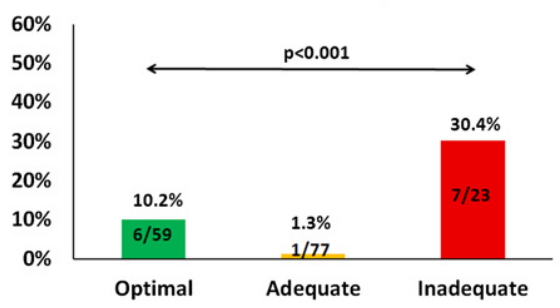

\% Late Re-intervention

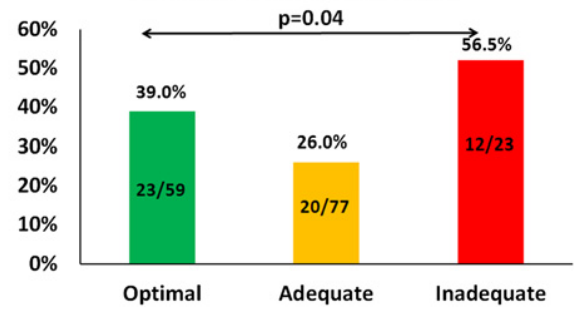

FIGURE E1. Relationship between Technical Performance Scores and late mortality and need for late reintervention. An inadequate Technical Performance Score was associated with a significantly greater late mortality and need for late reintervention.

\% Late Mortality

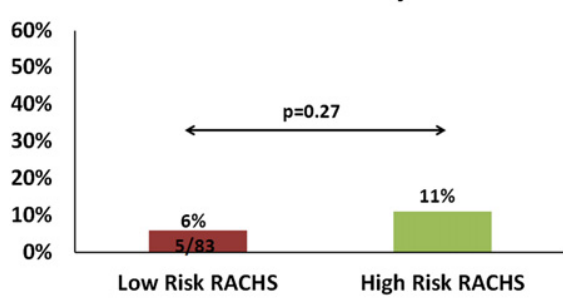

\% Late Re-intervention

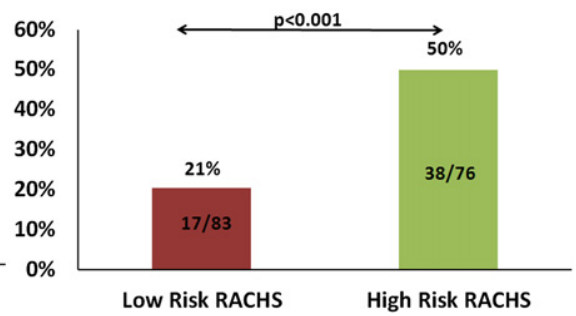

FIGURE E2. Relationship between Risk Adjustment for Congenital Heart Surgery-1 (RACHS-1) category and late mortality and need for late reinterventions. High-risk RACHS-1 category (RACHS-1 category 4-6) was associated with a significantly greater need for late reintervention. 

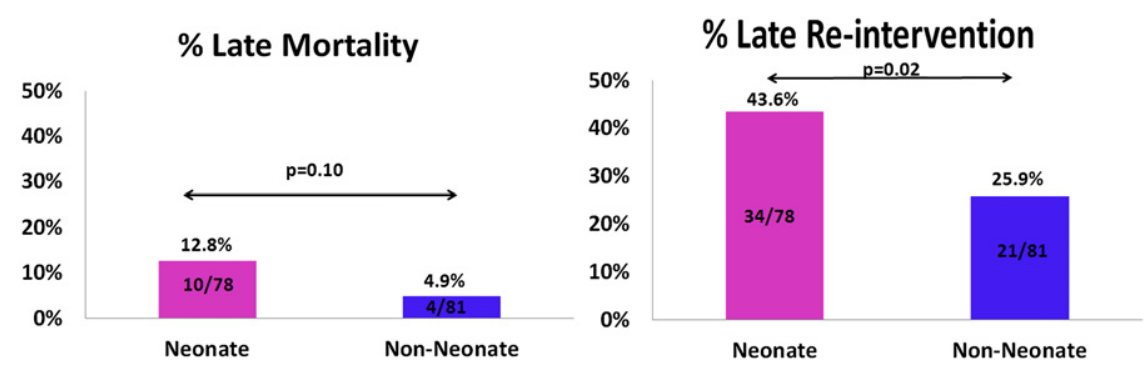

FIGURE E3. Relationship between neonates and late mortality and need for late reintervention. Neonatal age was associated with a significantly greater need for late reintervention.

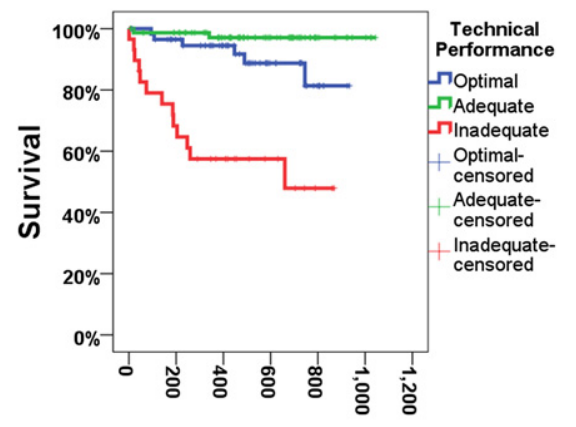

Follow-up (days)

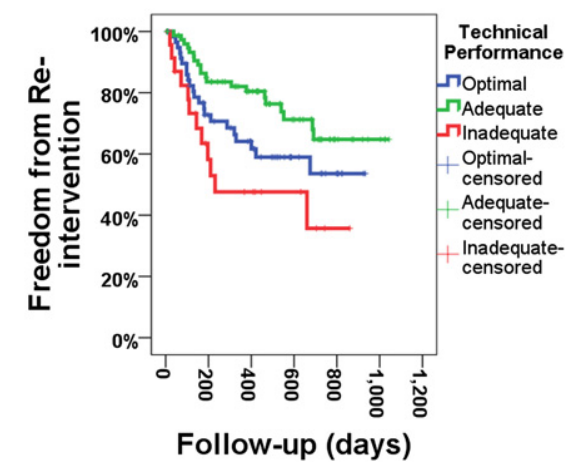

FIGURE E4. Kaplan-Meier curve representing freedom from late mortality and need for late reinterventions according to age at index surgery. Patients who were neonates at the index surgery had a significantly greater need for late reinterventions. 

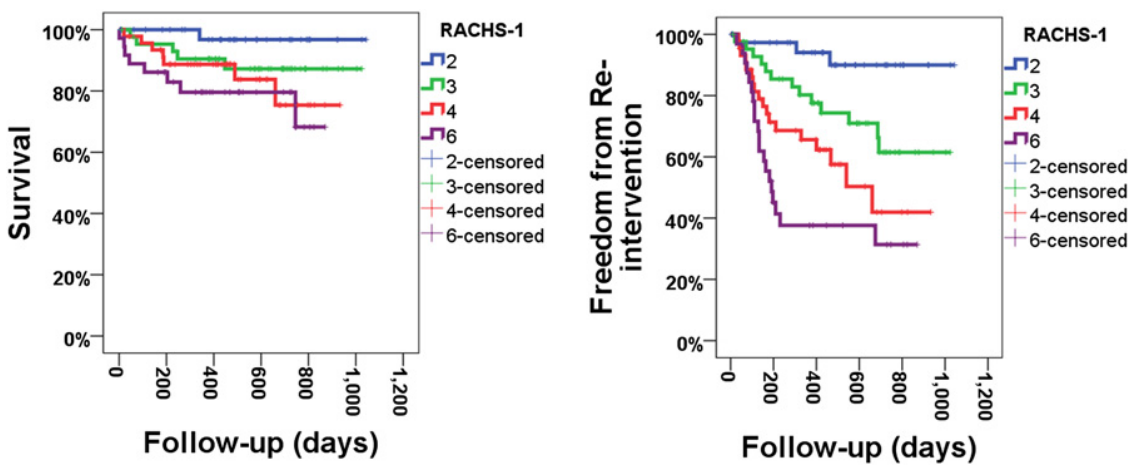

FIGURE E5. Kaplan-Meier curve representing freedom from late mortality and need for late reinterventions according to Technical Performance Score. Inadequate Technical Performance Score was associated with significantly greater late mortality and need for late reintervention. RACHS-1, Risk Adjustment for Congenital Heart Surgery-1.
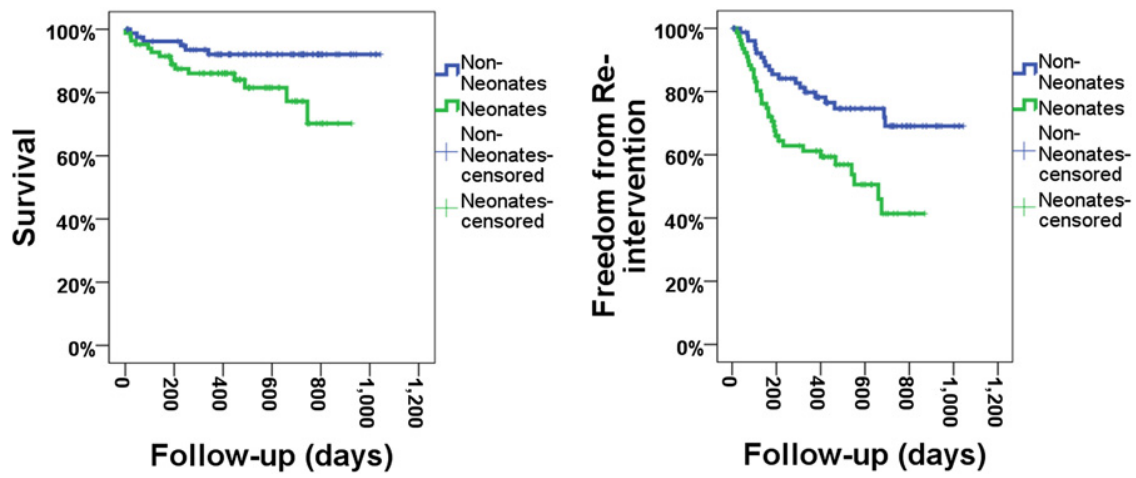

FIGURE E6. Kaplan-Meier curve representing freedom from late mortality and need for late reinterventions according to Risk Adjustment for Congenital Heart Surgery-1 (RACHS-1) category. High-risk RACHS-1 category (RACHS-1 category 4-6) was associated with a significantly greater need for late reintervention. 
TABLE E1. Distribution of RACHS-1 categories across TPS groups

\begin{tabular}{lccccr}
\hline & \multicolumn{4}{c}{ RACHS-1 category } & \\
\cline { 2 - 5 } \multicolumn{1}{c}{ TPS } & $\mathbf{2}$ & $\mathbf{3}$ & $\mathbf{4}$ & $\mathbf{6}$ & Total \\
\hline Optimal & $14(35 \%)$ & $10(24 \%)$ & $18(42 \%)$ & $17(50 \%)$ & 59 \\
Adequate & $26(65 \%)$ & $25(59 \%)$ & $15(35 \%)$ & $11(32 \%)$ & 77 \\
Inadequate & $0(0 \%)$ & $7(17 \%)$ & $10(23 \%)$ & $6(18 \%)$ & 23 \\
Total & 40 & 42 & 43 & 34 & 159 \\
\hline
\end{tabular}

RACHS-1, Risk Adjustment for Congenital Heart Surgery-1; TPS, Technical Performance Score. 
TABLE E2. Late reinterventions stratified by RACHS-1 category and TPS

\begin{tabular}{|c|c|c|c|c|}
\hline RACHS-1 category & Diagnosis & Procedure & TPS & Reintervention detail \\
\hline \multicolumn{5}{|l|}{ Category $6(\mathrm{n}=21)$} \\
\hline & HLHS & Stage I & 1 & $\mathrm{BD}$ of $\mathrm{CoA}, \mathrm{LPA}, \mathrm{OHT}$ \\
\hline & HLHS & Stage I & 1 & BD of CoA, TV-plasty at BDG \\
\hline & HLHS & Stage I & 1 & $\begin{array}{l}\text { Stenting of Sano, stenting of ASD } \\
\text { before BDG, atrial septectomy } \\
\text { at BDG }\end{array}$ \\
\hline & HLHS & Stage I & 1 & BD of ASD and PA, stenting of ASD \\
\hline & HLHS & Stage I & 1 & $\begin{array}{l}\text { Stenting of Sano, atrial septectomy } \\
\text { at BDG }\end{array}$ \\
\hline & HLHS & Stage I & 1 & Stenting of Sano \\
\hline & HLHS & Stage I & 1 & $\begin{array}{l}\text { Arch augmentation and pulmonary } \\
\text { vein debridement at BDG }\end{array}$ \\
\hline & HLHS & Stage I & 1 & Stenting of ASD and Sano \\
\hline & HLHS & Stage I & 1 & BD of ASD and PA, stenting of Sano \\
\hline & HLHS & Stage I & 1 & BD of innominate vein \\
\hline & HLHS & Stage I & 1 & BD of RPA, Sano stent \\
\hline & HLHC & Stage I & 1 & LPA stent \\
\hline & HLHS & Stage I & 2 & BD of Sano \\
\hline & HLHS & Stage I & 2 & Sano stent \\
\hline & HLHS & Stage I & 2 & Sano and ASD stent \\
\hline & UCAVC & Stage I & 2 & $\mathrm{BD}$ of $\mathrm{PA}$ and arch \\
\hline & UCAVC & Stage I & 2 & Atrial septectomy at BDG \\
\hline & HLHS & Stage I & 3 & $\mathrm{BD}$ arch and PA \\
\hline & HLHS & Stage I & 3 & $\begin{array}{l}\text { Upsize BTS, TV repair and PA-plasty, } \\
\text { pulmonary vein dilation }\end{array}$ \\
\hline & HLHS & Stage I & 3 & $\begin{array}{l}\text { BD of PA before BDG, BD of arch } \\
\text { after BDG, BD of MV }\end{array}$ \\
\hline & DILV, TAPVR & Stage I & 3 & BD of pulmonary veins \\
\hline \multicolumn{5}{|l|}{ Category $4(n=17)$} \\
\hline & Hypoplastic arch, VSD & Arch augment, PA band & 1 & $\begin{array}{l}\text { BD of PA band, surgical removal } \\
\text { of PA band }\end{array}$ \\
\hline & TAPVR & TAPVR repair & 1 & BD of pulmonary veins \\
\hline & HLHS & Comprehensive stage II & 1 & LPA stent \\
\hline & HLHS & Comprehensive stage II & 1 & $\begin{array}{l}\text { BD of ascending aorta, aortoplasty } \\
\text { at Fontan }\end{array}$ \\
\hline & Tet/PA/MAPCAS & Unifocalization & 1 & $\mathrm{BD}$ of PAs \\
\hline & UCAVC, CoA & Arch augmentation & 1 & AVV repair \\
\hline & IAA & IAA repair & 1 & $\mathrm{BD}$ of $\operatorname{arch}$ \\
\hline & $\mathrm{DOLV} / \mathrm{PA}$ & Rastelli & 1 & Late pacemaker for $2^{\circ}$ block \\
\hline & Truncus & Truncus repair & 2 & BD of PAs, PA-plasty, \\
\hline & Tet/PA/MAPCAS & Unifocalization & 2 & BD and conduit stent $\times 2$, BD PA \\
\hline & Tet/PA/MAPCAS & Unifocalization & 2 & Multiple PA rehabilitation, PVR \\
\hline & Heterotaxy, discontinuous PAs & Unifocalization & 2 & BD of PA, central PA-plasty at BDG \\
\hline & Hypoplastic arch, VSD & Arch augment, VSD closure & 2 & Sub-AS resection \\
\hline & TGA/VSD & ASO, VSD & 3 & OHT \\
\hline & TGA/VSD & ASO, VSD & 3 & BD of branch PAs \\
\hline & Tet/PA/MAPCAS & Unifocalization & 3 & PA rehabilitation \\
\hline & Truncus & Truncus repair & 3 & PA rehabilitation, PA-plasty \\
\hline \multicolumn{5}{|l|}{ Category $3(n=14)$} \\
\hline & Tet/PA & Repair with RV-PA conduit & 1 & Conduit change \\
\hline & $\begin{array}{l}\text { DORV, straddling TV and } \\
\text { hypoplastic RV }\end{array}$ & BTS & 1 & $\begin{array}{l}\text { Catheter to } \mathrm{BD}, \mathrm{PA} \text { after } \mathrm{BiV} \text { repair, } \\
\text { reoperation for residual } \mathrm{VSD}, \\
\text { pacemaker }\end{array}$ \\
\hline & HLHC & Aortic and mitral valve plasty & 1 & $\mathrm{BD}$ of $\mathrm{MV}$ \\
\hline & & & 1 & TV and mitral valve-plasty \\
\hline
\end{tabular}


TABLE E2. Continued

\begin{tabular}{|c|c|c|c|c|}
\hline RACHS-1 category & Diagnosis & Procedure & TPS & Reintervention detail \\
\hline & $\begin{array}{l}\text { Aortic regurgitation and } \\
\text { root dilation, } \mathrm{CT} \text { disorder }\end{array}$ & $\begin{array}{l}\text { Valve sparing; aortic root } \\
\text { replacement and ASC aortic } \\
\text { replacement }\end{array}$ & & \\
\hline & TOF/CAVC & Tet canal repair & 2 & BD of pulmonary valve and RPA \\
\hline & William's & Aortoplasty, MPA and LPA plasty & 2 & $\mathrm{BD}$ of PAs \\
\hline & TGA/IVS & ASO & 2 & BD of supra-PS \\
\hline & Tet/PA, single collateral & Tet PA repair with RV-PA conduit & 2 & $\begin{array}{l}\text { BD of distal conduit, conduit } \\
\text { change, stent in second conduit }\end{array}$ \\
\hline & CAVC & CAVC repair & 2 & Sub-AS resection \\
\hline & TOF/APV & Repair with RV-PA conduit & 2 & RPA BD, conduit change \\
\hline & Tricuspid atresia & BTS & 3 & $\begin{array}{l}\text { BD of PAs, PA-plasty at BDG, } \\
\text { PA-platy after BDG }\end{array}$ \\
\hline & CAVC & CAVC repair & 3 & Redo ASD and cleft closure \\
\hline & $\begin{array}{l}\text { Previous IAA repair with Ross } \\
\text { Konno, now with LCA } \\
\text { and conduit stenosis }\end{array}$ & $\begin{array}{l}\text { Intraoperative stenting of LCA, } \\
\text { conduit change }\end{array}$ & 3 & $\mathrm{BD}$ of PA, OHT \\
\hline & Tet/AVC & Tet canal repair & 3 & $\begin{array}{l}\text { ASD stent and BD } \\
\text { of pulmonary veins }\end{array}$ \\
\hline \multicolumn{5}{|l|}{ Category $2(\mathrm{n}=3)$} \\
\hline & TOF & TOF repair & 2 & BD of supra-PS \\
\hline & TOF & TOF repair & 2 & BD of RVOT \\
\hline & Pulmonary atresia/IVS, after BTS & BDG & 2 & $\begin{array}{l}\text { BD to rehabilitation PA, stenting } \\
\text { of PA, BD of SVC anastomosis } \\
\text { to PA }\end{array}$ \\
\hline
\end{tabular}

RACHS-1, Risk Adjustment for Congenital Heart Surgery-1; TPS, Technical Performance Score; $H L H S$, hypoplastic left heart syndrome; $B D$, balloon dilation; CoA, coarctation of aorta; $L P A$, left pulmonary artery; $O H T$, orthotopic heart transplantation; $T V$, tricuspid valve; $B D G$, bidirectional Glenn; $A S D$, atrial septal defect; $P A$, pulmonary artery; $R P A$, right pulmonary artery; $U C A V C$, unbalanced complete atrioventricular canal; BTS, Blalock-Taussig shunt; $M V$, mitral valve; DILV, double inlet left ventricle; VSD, ventricular septal defect; TAPVR, total anomalous pulmonary venous return; Tet, tetralogy; $R V$, right ventricle; $A S O$, arterial switch operation; $T G A$, transposition of great arteries; $P S$, pulmonary stenosis; $M A P C A$, major aortopulmonary collateral; $A V C$, atrioventricular canal; $I A A$, interrupted aortic arch; $D O L V$, double outlet left ventricle; $B i V$, biventricular; $C T$, connective tissue; $T O F$, tetralogy of Fallot; RVOT, right ventricular outflow tract; $C A V C$, complete atrioventricular canal; $M P A$, main pulmonary artery; $L C A$, left coronary artery; $S V C$, superior vena cava; $H L H C$, hypoplastic left heart complex; $A V V$, atrioventricular valve; IVS, intact ventricular septum.

TABLE E3. Late mortality/transplantation and relationship to late reinterventions

\begin{tabular}{lccc}
\hline & \multicolumn{2}{c}{ Late mortality } & \\
\cline { 2 - 3 } Late reintervention & Alive & Dead & Total \\
\hline No & 98 & 6 & $104(6 \%)$ \\
Yes & 47 & 8 & $55(15 \%)$ \\
Total & 145 & 14 & 159 \\
\hline
\end{tabular}

TABLE E4. Effect of stratified TPS, by age and then RACHS-1 category for late death/transplantation

\begin{tabular}{|c|c|c|c|}
\hline Variable & Patients (n) & Deaths (n) & $P$ value \\
\hline \multicolumn{4}{|l|}{ Neonate } \\
\hline TPS & & & .02 \\
\hline Optimal/adequate & 63 & $5(7.9 \%)$ & \\
\hline Inadequate & 15 & $5(33.3 \%)$ & \\
\hline \multicolumn{4}{|l|}{ Non-neonate } \\
\hline TPS & & & .05 \\
\hline Optimal/adequate & 73 & $2(2.7 \%)$ & \\
\hline Inadequate & 8 & $2(25.0 \%)$ & \\
\hline \multicolumn{4}{|l|}{ RACHS category 2-3 } \\
\hline TPS & & & .05 \\
\hline Optimal/adequate & 76 & $3(4.0 \%)$ & \\
\hline Inadequate & 7 & $2(28.6 \%)$ & \\
\hline \multicolumn{4}{|l|}{ RACHS category 4-6 } \\
\hline TPS & & & .02 \\
\hline Optimal/adequate & 60 & $4(6.7 \%)$ & \\
\hline Inadequate & 16 & $5(31.3 \%)$ & \\
\hline
\end{tabular}


TABLE E5. Effect of TPS, stratified by age and RACHS-1 category for late reintervention

\begin{tabular}{lccc} 
late reintervention & & & \\
\hline \multicolumn{1}{c}{ Variable } & Patients (n) & Late reintervention (n) & $\begin{array}{c}\boldsymbol{P} \\
\text { value }\end{array}$ \\
\hline Neonate & & & \\
$\quad$ TPS & & & 1.0 \\
$\quad$ Optimal/adequate & 63 & $7(42.9 \%)$ & \\
$\quad$ Inadequate & 15 & & \\
Non-neonate & & & .03 \\
TPS & & $5(62.5 \%)$ & \\
$\quad$ Optimal/adequate & 73 & & .03 \\
$\quad$ Inadequate & 8 & $13(17.1 \%)$ & \\
RACHS Category 2-3 & & $4(57.1 \%)$ & \\
TPS & & & \\
$\quad$ Optimal/adequate & 76 & $30(50.0 \%)$ & \\
$\quad$ Inadequate & 7 & $8(50.0 \%)$ & \\
RACHS category 4-6 & & & \\
TPS & & & \\
$\quad$ Optimal/adequate & 60 & & \\
Inadequate & 16 & & \\
\hline
\end{tabular}

$\overline{T P S}$, Technical Performance Score; RACHS-1, Risk Adjustment for Congenital Heart Surgery-1 